

\section{REVISTA \\ TEORÍA Y PRÁCTICA \\ DE LA \\ ARQUEOLOGÍA HISTÓRICA LATINOAMERICANA}

ISSN: 2250-866X (impreso) | ISSN: 2591-2801 (en línea)

AÑO VIII, VOLUMEN 9, PRIMAVERA DE 2019

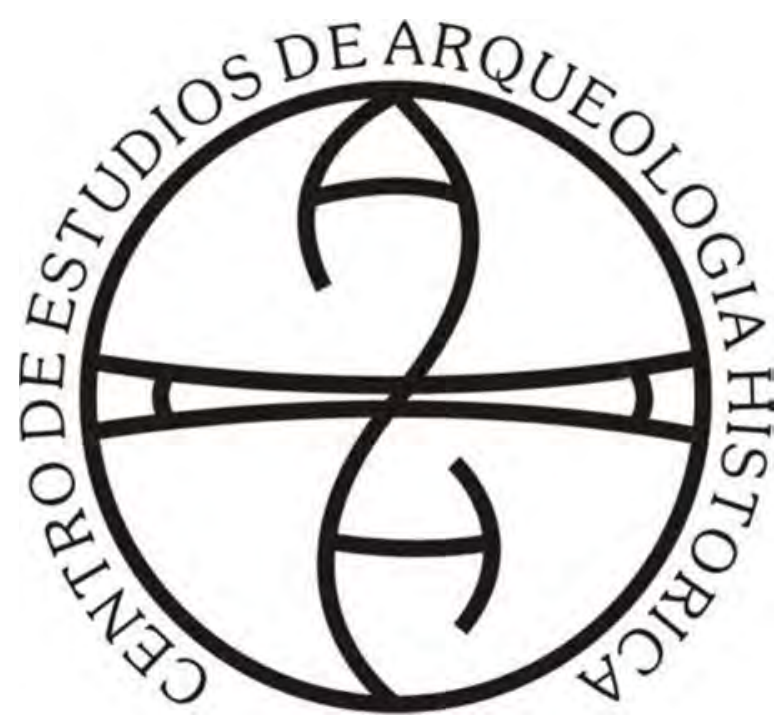

CENTRO de Estudios de ARqueOlOGía HistóricA

FACULTAD DE HUMANIDADES Y ARTES | UNIVERSIDAD NACIONAL DE ROSARIO 
(Universidad Nacional de Rosario, Universidad Nacional de Río Cuarto,

Universidad Nacional de San Juan, Universidad de la República, Universidad Nacional de Trujillo)

\author{
AUTORIDADES DE LA UNIVERSIDAD NACIONAL DE ROSARIO \\ RECTOR: Lic. Franco Bartolacci \\ VICE-RECTOR: Od. Darío Macía \\ SECRETARIO GENERAL: Prof. José Goity \\ SECRETARIA ACADÉMICO Y DE APRENDIZAJE: Dr. Marcelo Vedrovnik \\ SECRETARÍA DE CIENCIA TECNOLOGÍA E INNOVACIÓN \\ PARA EL DESARROLLO: Ing. Guillermo Montero.
}

\author{
AUTORIDADES DE LA FACULTAD DE HUMANIDADES Y ARTES \\ DECANO: Prof. Alejandro Vila \\ VICEDECANA: Prof. Marta Varela \\ SECRETARIA ACADÉMICA: Dra. Marcela Coria
}

\author{
AUTORIDADES DEL CENTRO DE ARQUEOLOGÍA HISTÓRICA \\ DIRECTORA: Dra. Ana Rocchietti \\ SECRETARIA: Prof. Nélida de Grandis \\ PROSECRETARIA: Lic. Marianela Bizcaldi
}

DIRECTORAS - EDITORAS:

Dra. Ana Rocchietti y Prof. Nélida De Grandis

SECRETARIA DE EDICIÓN: Dra. Irene Dosztal

Este número es co-edición de las ponencias

del VIII Congreso Nacional de Arqueología Histórica (2018) entre:

Centro de Estudios en Arqueología Histórica: Directora Ana Rocchietti

Centro de Estudios en Arqueología Regional: Director Fernando Oliva

Centro de Estudios en Arqueología Subacuática: Directora Mónica Valentini

Departamento de Arqueología, Escuela de Antropología: Director Fernando Oliva
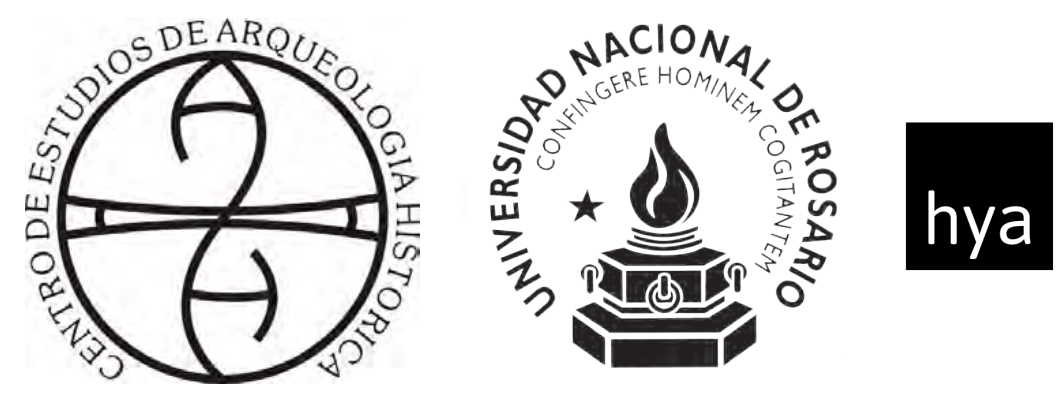

Facultad de Humanidades

y Artes_UNR
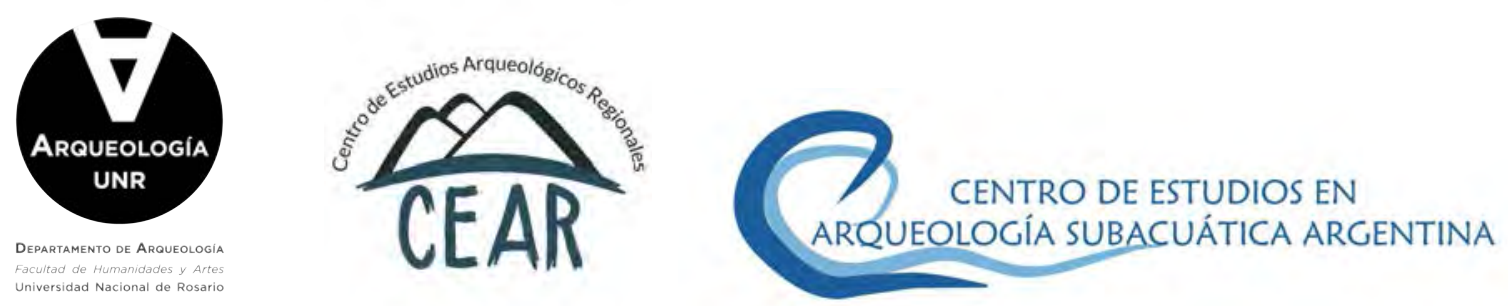
Comité Permanente de los Congresos Nacionales de Arqueología Histórica

Dr. Daniel Schávelzon (Universidad Nacional de

Buenos Aires)

Prof. María Teresa Carrara (Universidad Nacional de Rosario)

Prof. Carlos Baldassarre (Museo Municipal de Río

Grande, Tierra del Fuego) in memoriam

Dr. Mariano Ramos (Universidad Nacional de Luján, CONICET)

Dr. Horacio Chiavazza (Universidad Nacional de Cuyo)

Dra. Ana María Rocchietti (Universidad Nacional de

Rosario, Universidad Nacional de Río Cuarto)

Lic. Facundo Gómez Romero (Universidad Autónoma

de Barcelona)

\section{Comité Científico}

Dra. Tânia Andrade Lima (Universidade Federal do Rio de Janeiro)

Prof. Réginald Auger (CELAT/Département des

Sciences Historiques, Université Laval, Canadá)

Dr. Roberto Bárcena (Universidad Nacional de Cuyo, CONICET)

Dra. Marta Bonaudo (Universidad Nacional de Rosario, CONICET)

Dr. Leonel Cabrera (Universidad de la República, Uruguay)

Dr. Luis María Calvo (Universidad Católica de Santa

$\mathrm{Fe})$

Prof. Juan Castañeda Murga (Universidad Nacional de

Trujillo, Perú)

Dr. Carlos Ceruti (Museo de Ciencias Naturales y

Antropología "Prof. Antonio Serrano”. Paraná)

Dr. Horacio Chiavazza (Universidad Nacional de Cuyo)

Dra. Silvia Cornero (Universidad Nacional de Rosario)

Prof. Pedro Paulo Funari (Universidade Estadual de

Campinas, Brasil)

Lic. Jorge A. Gamboa Velásquez (Universidad Nacional

Santiago Antuñez de Mayolo, Perú)

Dr. Eduardo Alejandro García (Universidad Nacional de

San Juan, CONICET)

Prof. Nélida De Grandis (Universidad Nacional de

Rosario)

Dr. Juan Bautista Leoni (Universidad Nacional de

Rosario, CONICET)

Dra. Amancay Martínez (Universidad Nacional de San

Luis)

Dra. Catalina Teresa Michieli (Universidad Nacional de

San Juan, CONICET)

Lic. Fernando Oliva (Universidad Nacional de Rosario)
Ing. Adrián Pifferetti (Universidad Tecnológica Nacional Regional Rosario)

Dr. Mariano Ramos (Universidad Nacional de Luján, CONICET)

Dra. Ana María Rocchietti (Universidad Nacional de Rosario)

Dr. Daniel Schávelzon, (Universidad Nacional de Buenos Aires, CONICET)

Dra. Carlota Sempé (Universidad Nacional de La Plata)

Dr. Mario Silveira (Universidad Nacional de Buenos

Aires)

Dra. Silvia Simonassi (Universidad Nacional de Rosario)

Dra. Alicia Tapia (Universidad Nacional de Buenos Aires, Universidad Nacional de Luján)

Lic. Mónica P. Valentini (Universidad Nacional de Rosario)

Agrim. Benito Vicioso (Universidad Nacional de Rosario)

\section{Evaluaron este volumen}

Roberto Bárcena, María Teresa Boschin, Leonel Cabrera, Ulises Camino, María Rosa Carbonari, Carlos Ceruti, Horacio Chiavazza, Nicolás Ciarlo, Silvia Cornero, Eduardo Crivelli, Javier García Cano, Martín Gentinetta, María Laura Gili, Carlos Landa, Matilde Lanza, Melina Malandrino, Sebastián Pastor, Victoria Pedrotta, Josefina Piana, Mercedes Podestá, Mariano Ramos, Daniel Schavelzon, Diana Tamburini, Mónica Therrien, Mónica Valentini y María Teresa Boschin

\section{Diseño y diagramación}

Eugenia Reboiro

(eugenia.reboiro@gmail.com)

\section{Curadoría}

Ana Rocchietti e Irene Dosztal

Foto de tapa: Material arqueológico, del texto de Tapia et al.

\section{Propietario responsable:}

Facultad de Humanidades y Artes, Universidad Nacional de Rosario Centro de Estudios de Arqueología Histórica

Entre Ríos 758. Rosario, provincia de Santa

Fe (2000). Argentina.

Telf.: +54 (0341) 4802670

E-mail: ceahunr@gmail.com

Decreto Ley 6422/57 de Publicaciones

Periódicas 


\section{Índice}

Editorial

El origen del patrimonio histórico y su conservación integral en la contemporaneidad.

Yanina Aguilar

Prospección de basurales históricos de la ciudad de Rosario.

Soccorso Volpe y Gustavo Fernetti

Desconstrucción de un paisaje urbano. El Montevideo del extramuros colonial, aportes de la arqueología a su identidad actual. Ana Gamas

La Calota de Ameghino: reconsiderando un viejo tema desde la arqueología histórica.

Daniel Schávelzon

Análisis zooarqueológico de los restos hallados en una estructura sanitaria vinculada a momentos tempranos del actual barrio de Belgrano .71 Mario Silveira, Horacio Padula, Ricardo Orsini y Eva Bernat

La medida del tiempo: el reloj solar jesuita de La Cruz, provincia de Corrientes.

Fernando Oliva y María Cecilia Panizza

Sitio La Quinta: arqueología rural de campos serranos.

Flavio Ribero

Si no hay tabaco que no se note. Prácticas fumatorias en el fortin La Perra (1883-1885), La Pampa.

Alicia Tapia, Virginia Pineau y Melisa Ayelén Auge

El uso del tabaco y las pipas de caolin (clay pipes) en la frontera sur y oeste de la provincia de Buenos Aires en el siglo XIX.. .127

María del Carmen Langiano y Julio Fabián Merlo 
Patrimonio natural, urbano y arquitectónico de la costa en Mar del Plata. Federico Negroni

Huellas urbanas.

Ezequiel Serrot

Paisaje y patrimonio. La industria taninera en el siglo XX.

Provincia de Santa Fe.

Cristina Pasquali, Paola Milicic y Lara Ferré

Los desafíos de las arqueologías históricas latinoamericanas.

Andrés Zarankin

Sellos entre escombrales. Las lozas en el registro urbano

del Área Fundacional de Mendoza (siglo XIX y principios del siglo XX)

Lorena Puebla y Horacio Chiavazza

Evolución edilicia de la Plaza de Mayo de la Ciudad

de Buenos Aires (1580-1853).

Nicolás Ferrino

Gestión patrimonial en el rescate arqueológico y futuro Museo de Sitio

en Moreno 550, Ciudad Autónoma de Buenos Aires, Argentina.

María Eva Bernat, Ricardo Orsini, Horacio Padula y Mario Silvera 


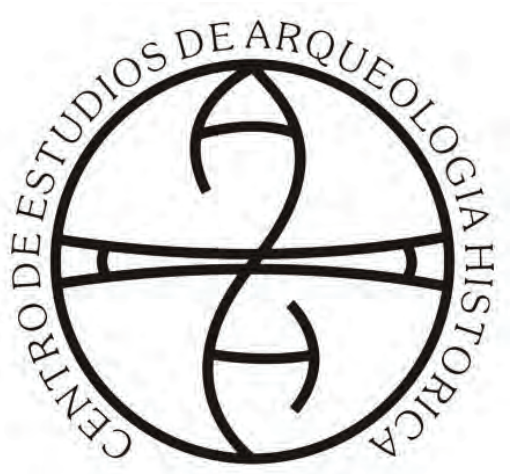

Centro de Estudios de Arqueología Histórica

Universidad Nacional de Rosario
Teoría y Práctica de la Arqueología Histórica

Latinoamericana | Año VIII. Vol. 8 | 2019

Revista del Centro de Estudios de Arqueología

Histórica, Facultad de Humanidades y Artes, Universidad Nacional de Rosario

https://teoriaypracticaah.unr.edu.ar/index.php/index ceahunr@gmail.com

ISSN en línea: 2591-2801

ISSN versión impresa: 2250-866X

\title{
Huellas urbanas
}

\author{
Ezequiel Serrot*
}

\section{Resumen}

Para englobar varios de los subtemas que me propongo presentar en el siguiente y pensando en mi aporte como Arquitecto en el conocimiento de la historia de la ciudad, en particular de la Ciudad de Buenos Aires, es que busqué un concepto que pudiera ineludiblemente hacer referencia a aquellas marcas que, el paso del tiempo, producen en la trama urbana.

Para llegar a entender o ver las huellas urbanas en las ciudades, es preciso primero conocer aquellas cosas que las han generado, para eso es vital recorrerlas en sus orígenes, entender su funcionamiento o razón de ser en sus contextos originales. Muchas veces también se debe comprender como ante nuevos desafíos y contextos muy distintos a los originales han llevado a su desmantelamiento, como en el caso de ferrocarriles, o su entubamiento en el caso de arroyos.

Es por eso que antes de ver las huellas, me permito en cada caso mostrar los elementos que las originaron, en distintos contextos del pasado apelando a imágenes de cartografía del siglo XIX, imágenes de fotografía aérea de mediados del siglo XX y finalmente imágenes satelitales del siglo XXI.

Palabras clave: Huella - Registro - Testigo - Trama urbana

\begin{abstract}
To gather several of the subtopics that I propose to present in the following and thinking about my contribution as an Architect in the knowledge of the history of the city, in particular of the City of Buenos Aires, I looked for a concept that could inevitably refer to those brands that, over time, produce in the urban plot.

To get to understand or see the urban footprints in the cities, it is necessary first to know those things that have generated them, for that it is vital to travel them in their origins, to understand their operation or reason of being in their original contexts. Many times it must also be understood how new challenges and contexts very different from the original ones have led to their dismantling, as in the case of railways, or their casing in the case of streams.
\end{abstract}

* Universidad de Buenos Aires - Facultad de Arquitectura, Diseño y Urbanismo. ezequielserrot@gmail.com 
That is why before seeing the footprints, I allow myself in each case to show the elements that originated them, in different contexts of the past appealing to cartography images of the nineteenth century, aerial photography images of the mid-twentieth century and finally satellite images of the XXI century.

Keywords: Footprint - Registration - Witness - Urban plot

Huella: "Señal o rastro que queda de una cosa o de un suceso."1

\section{Introducción}

Pensé en el concepto de "huella", tomando como tal al rastro que queda luego de un suceso o de una cosa de una generación a otra.

Me alejé así de una primera idea de hablar sobre las "cicatrices" urbanas, dado que por definición la cicatriz es el resultado de una herida, dándole así una connotación negativa a los hechos que las provocaron, cuando a mi parecer estos hechos más que herir a la ciudad, la hacer evolucionar... a veces retroceder, a veces crecer pero eso es lo que le da vida a las ciudades.

Huella, aunque puede ser tomado livianamente en su acepción más cotidiana de marca que queda en el piso o camino, es a mí entender una definición más justa de aquellos rastros que quedan de algunos elementos antiguos en las ciudades de hoy en día.

Varios son los posibles orígenes de estas huellas, me he concentrado principalmente en tres elementos que entiendo resumen cabalmente las transformaciones que viven las ciudades. En primer lugar los ferrocarriles, tanto sus trazados en funcionamiento como los tramos desafectados suelen justificar muchos de los aspectos compositivos de la trama urbana. Los arroyos, entre otros elementos de origen natural del entorno previo a la intervención del hombre, tales como accidentes geográficos, elevaciones, depresiones y demás formas, son también en la medida en que fueron siendo entubados y eliminados de la vista, los generadores de nuevas vialidades dado que sus nuevas estructuras de "techo" sirven de forma eficiente a la conducción de autos. Finalmente analizo una tipología de equipamiento deportivo, que como veremos también es fuente de huellas urbanas.

\section{Los ferrocarriles}

A lo largo de la historia de la Ciudad, varios son los ramales ferroviarios que fueron instalados y levantados en diferentes momentos. De esos viejos trazados quedan varias huellas, de diferente tipo, algunas son más visibles otras sólo para el ojo entrenado en cuestiones de catastro. Muchas calles y lotes con formas y direcciones caprichosas a priori, encuentran su razón o justificación si se las entiende como huellas del pasado.

El crecimiento de la ciudad y la progresiva incorporación de chacras o grandes extensiones desocupadas a la trama urbana, provocó una transformación doble. Por un lado se encuentra la apertura de nuevas calles y avenidas para mejorar la circulación y dar accesibilidad a los nuevos loteos. Por otro lado, se encuentra la negativa de los nuevos vecinos a convivir con instalaciones de equipamiento urbano de características industriales, como los ramales ferroviarios de carga y no de pasajeros.

Mientras que unos resolverían los problemas de conectividad con el centro, los de uso técnico generalmente producen más molestias que soluciones para con sus vecinos inmediatos. Ramales de carga de elementos industriales, basura y otras cargas como ganado o cereales generan malestar en entornos 
más urbanos, y son generalmente relegados a la periferia de las ciudades. Ahora bien, con una ciudad en permanente crecimiento y que se encuentra corriendo sus límites en forma constante, suele ocurrir como en la Ciudad de Buenos Aires que en algunos momentos de su historia, mientras se urbanizan algunos sectores todavía se encontraban en uso ramales ferroviarios de servicios de carga.

Es mediante este doble proceso de urbanización y traslado de instalaciones de carácter más periurbano, que algunos de los lugares vacantes dejados por estas últimas vuelvan a ser aprovechados por la trama urbana para resolver problemas de conectividad o circulación.

Concretamente, el desmonte o desarmado de vías férreas de ramales o tramos en desuso, puede ser visto como una oportunidad para o bien abrir calles o avenidas, o bien lotear esos terrenos y darlos a la vida urbana.

Como en nuestra ciudad, ha ocurrido tanto una como otra cosa, es que seleccioné algunos casos que resumen estas particularidades, que a su vez reafirman el carácter de huella que he venido planteando.

Un elemento que en la actualidad puede verse con forma, dirección y trazado caprichoso, entiende en viejos recorridos ferroviarios el origen de dichas formas.

\section{Las Pueyrredón}

La Ciudad de Buenos Aires tiene dos Avenidas Pueyrredón, una en homenaje a Juan Martín de Pueyrredón, militar y político argentino que fuera Director Supremo de las Provincias Unidas del Río de la Plata.

La otra a su sobrino nieto, el jurisconsulto, profesor universitario, político y diplomático Honorio Pueyrredón. Ambas deben su trazado a antiguos ramales ferroviarios desafectados y convertidos en vías de circulación.

La Av. Pueyrredón (Juan Martín) está ubicada en Recoleta, y sigue el trazado del viejo "ferrocarril de la basura”, un ramal que unía la Estación Central ubicada en el bajo (actual Av. Leando N. Alem y Bartolomé Mitre) con la zona de "la quema” donde hoy se ubican al Estación Buenos Aires del FFCC Belgrano Sur y el Estadio Tomás Adolfo Ducó del Club Atlético Huracán. Este era el destino final de ese ramal, donde literalmente se quemaba la basura para el año 1873, año de su inauguración, no sin antes pasar por las estaciones de Retiro y Once a donde tomaba también carga.

Algunos vestigios del trazado y de la lógica de circulación del sistema ferroviario, pueden verse aún, dado que para producir los giros o curvas del recorrido, las formaciones necesitan radios de curvatura mayores que los automóviles. Es por eso, que el tramo inicial de la Av. Pueyrredón donde nace desprendiéndose de la actual Av. Figueroa Alcorta, presenta una curva hoy ocupada por la Plaza Dante y no un giro a $90^{\circ}$ que no sería imposible de sortear por los automovilistas pero que era inviable para las formaciones del siglo pasado.

Otra huella puede verse en otro giro que se producía para tomar el rumbo necesario (Sur), y además pasar frente a la estación Once. A la altura de la actual calle Peña, se percibe como la Av. Pueyrredón toma un leve giro y la calle Anchorena nace como continuación de la grilla o damero de calles habituales, evidenciando que la que cambia de rumbo es la estudiada avenida.

Como particularidad, el centenario Hospital Alemán que actualmente se ubica sobre la avenida entre las calles Juncal y Beruti, tiene en su hall principal un fresco que ilustra el paisaje de la zona al momento de la fundación de la institución hacia 1867 y en el mismo se pueden ver tanto las vías como una formación del ferrocarril recorriéndolas.

Hacia finales del S.XIX, la zona presentaba muchos cambios, se habían abierto numerosas calles y se lotearon las zonas aledañas a la Avenida, convirtiendo de a poco a esta otrora zona alejada en un barrio 
Teoría y Práctica de la Arqueología Histórica Latinoamericana | Año VIII. Vol. 9 | 2019

ISSN en línea: 2591-2801 | ISSN versión impresa: 2250-866X

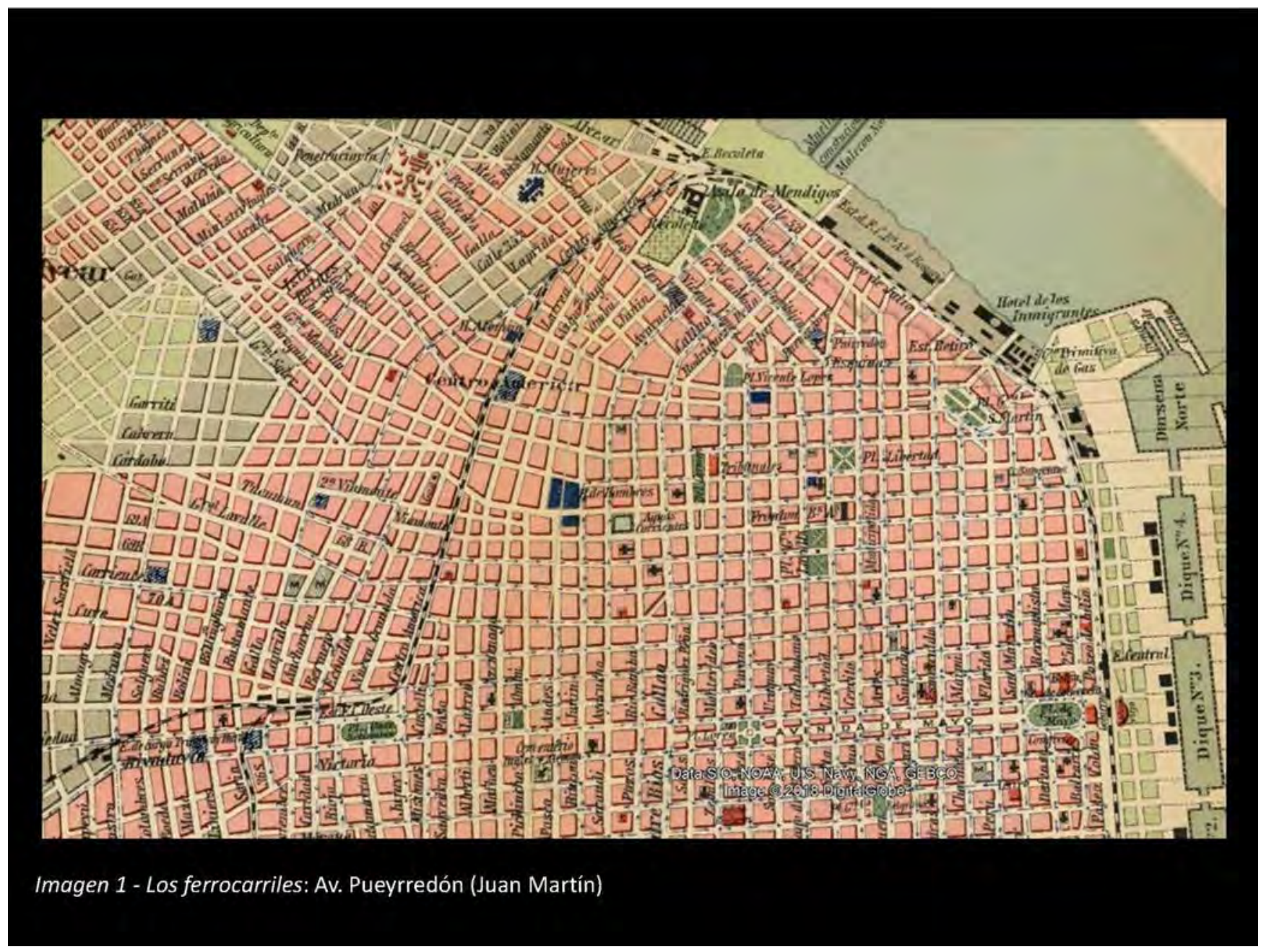

residencial. La fiebre amarilla, provocó la expulsión de los habitantes más pudientes del sur de la ciudad y éstos se reubicaban en la zona norte, entre ellas las áreas linderas con el ferrocarril.

El pasaje de zona alejada y permeable de recibir estructuras de servicio como un ferrocarril de traslado de basura a barrio residencial hizo necesario por un lado reubicar el tendido ferroviario a un sector aún más alejado y por otro se planteaba la necesidad de contar con arterias de circulación más ágiles y cómodas.

Es por eso que se decide desmantelar el tendido existente del ferrocarril y convertir así la franja liberada en la Avenida Centro América, denominación que cambió hacia 1902 por la actual.

En el completo sistema ferroviario que supimos tener, era muy frecuente encontrar con ramales de vinculación o interconexión, para que formaciones de una línea pudieran pasar a otra. Claro estaba debían compartir el ancho de trocha. Generalmente las empresas extranjeras que construyeron y operaron en sus primeros momentos (la mayoría de los ferrocarriles fueron estatizados recién a mediados de la década del '40) los ferrocarriles eran de origen inglés y optaron por el mismo ancho de trocha de sus servicios en Gran Bretaña.

Estos ramales, de pocos kilómetros o a veces incluso cientos de metros de extensión, permitían por ejemplo el envío de formaciones a talleres que se ubicaban en las afueras de la ciudad en alguna de las 
líneas, la llegada de mercaderías de una provincia a los mercados de abasto, y luego cambiando de ramal redirigirse nuevamente a otra provincia (por ejemplo viniendo por el Ferrocarril al Pacífico y combinar con el tren a Rosario). Sus trazados lejos de ser caprichosos, presentan numerosas curvas, dado que saliendo de la dirección de un ramal, deben lograr con los radios ya mencionados comunicarse con el otro.

Tal es el caso de la Av. Honorio Pueyrredón, ubicada en los barrios de Caballito y Villa Crespo, que es la huella del viejo trazado que desde 1895 funcionaba como vía de interconexión entre el Ferrocarril al Pacífico (actual San Martín) y el Ferrocarril del Oeste (actual Sarmiento), al que pertenecía.

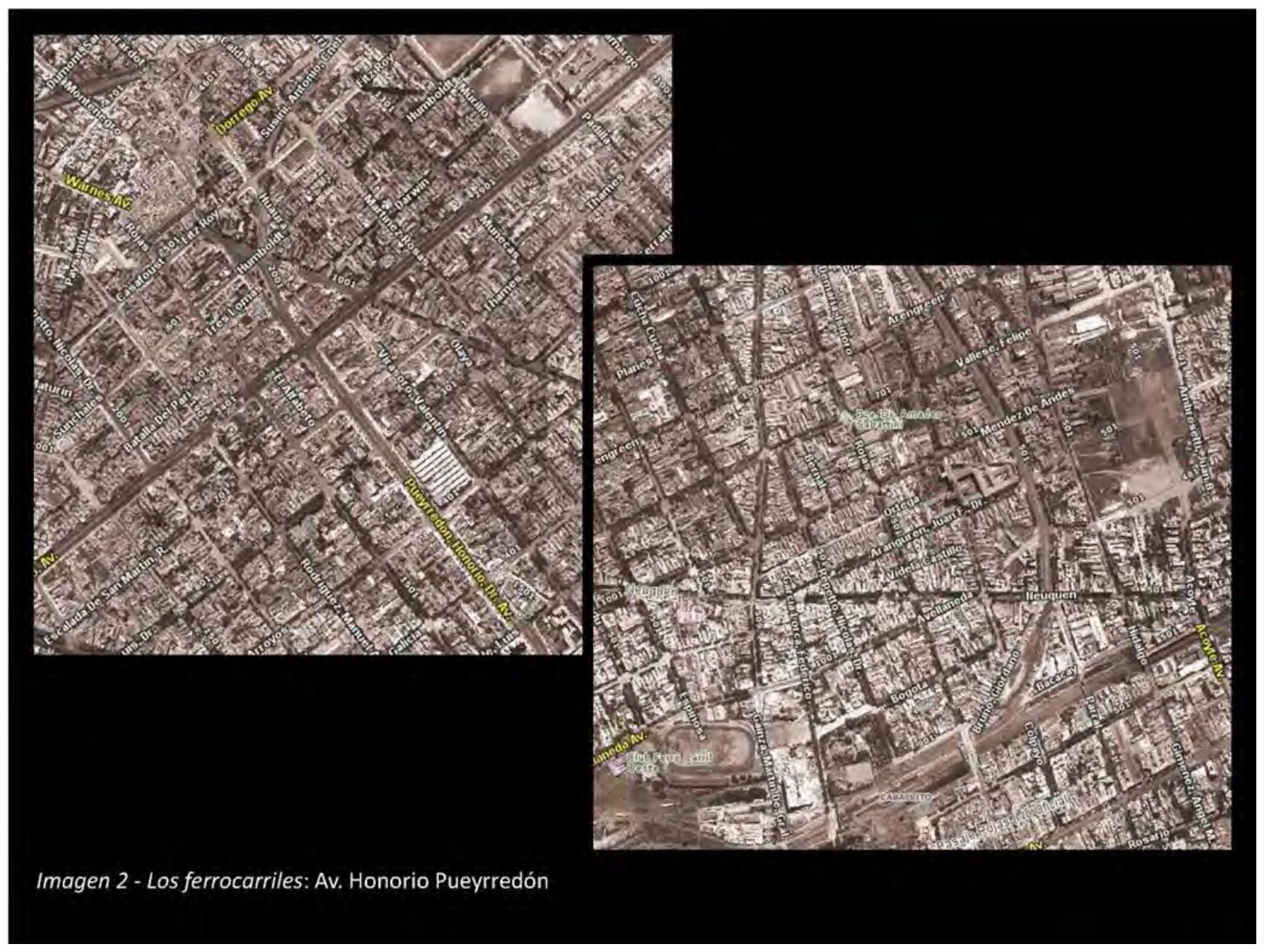

Esta conexión duró solo unos 30 años, dado que el avance de la trama urbana hizo necesario cada vez más una vía de circulación vehicular a una unión con uso poco frecuente entre ramales. Con el crecimiento de la ciudad, estos tramos de conexión fueron también reubicados más en las afueras de la trama, hoy por ejemplo estos ferrocarriles cuentan con una conexión entre las estaciones de Caseros (FFCC San Martín) y Haedo (FFCC Sarmiento).

En el año 1926, el ramal fue levantado por pedido de la Intendencia Municipal, para convertirse en una vía de circulación, como se mencionó antes, conocida como Av. Parral, fue cambiado su nombre al actual en el año 1959. 
Resulta interesante, entender que como ramal de conexión, presenta un tramo recto en el centro, ocupado ahora por la actual Avenida, donde tiene una fisionomía tradicional, pero sus extremos son curvos, respetando las posibilidades de giro de los trenes. El extremo norte luego de cruzar la Av. Warnes se convirtió en la calle Cnel. Antonio Susini y el extremo sur, en la calle Giordano Bruno, que aprovechando el ancho generoso de la traza en su conexión con el FFCC Sarmiento, genera un parque lineal a su lado.

Dadas las medidas de las formaciones, los anchos de paso y sobrepaso utilizando a veces 3 vías, para mediante cambios poder adelantar una formación a otra, sumado a los gálibos de seguridad requeridos habitualmente en el diseño de tendidos ferroviarios, queda como resultado que al desmontarse un ramal la traza liberada presenta un ancho generoso que permitió en estos dos casos mencionados, como en tantos otros su reconversión en Avenidas, en lugar de pequeños pasajes o calles angostas.

\section{De Once a Dock Sud}

\section{(Sanchez de Loria-Oruro-Deán Funes-Zavaleta)}

Las cuatro calles actuales del subtítulo, al margen de ser una la continuación de la otra, son la huella del "ferrocarril de la basura” que originó la primera Av. Pueyrredón, mencionada más arriba.

Luego de pasar por la Estación Once, el trazado en lugar de tomar la dirección que toma la Av. Jujuy (continuación de la Av. Pueyrredón) continuaba por las actuales Sanchez de Loria, tomaba una curva hacia el Este, lo que explica el trazado curvo de la calle Oruro y se rectificaba hacia el Riachuelo originando la actual calle Deán Funes que luego cambia de nombra a Zavaleta. En una conexión prevista con el Ferrocarril del Sur y los talleres de mantenimiento ubicados en Avellaneda, un ramal cruzaba el Riachuelo tomando luego una curva hacia el Este con destino final al puerto de Dock Sud.

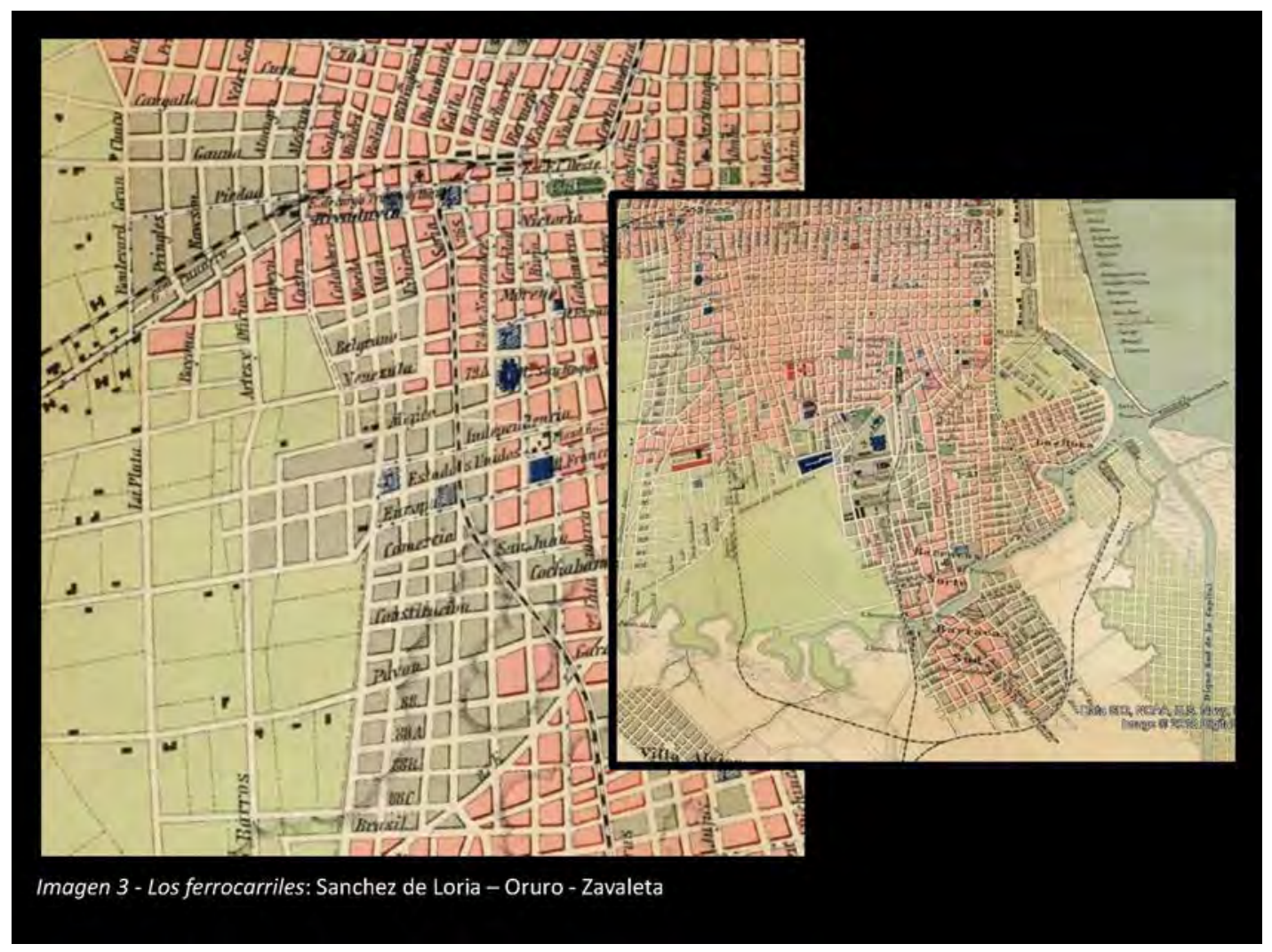


El tramo de Sánchez de Loria, podría decirse es el más simple. Una traza recta donde el desmantelado del ramal de la basura por los motivos ya contados, origina una nueva vía de circulación vehicular. Esto cambia la llegar a la actual Plaza Boedo, donde la calle tiene un desvío y donde precisamente nace la siguiente calle "huella" del trazado.

Cabe destacar que hasta no hace mucho tiempo, dicha plaza no existía, sino que se ubicaban unos galpones donde funcionaba en sus últimos años una terminal de colectivos, pero que su uso original era una estación de guarda de tranvías. El vínculo de la zona con lo ferroviario, viene entonces desde el origen dado que el ferrocarril original pasaba por el lateral de estar estación.

Siguiendo la traza, ocurre aquí un pequeño giro hacia el este, con una curva, un tramo diagonal y otra curva, que es lo que explica la particular dirección de la calle Oruro, totalmente distinta a la trama urbana circundante.

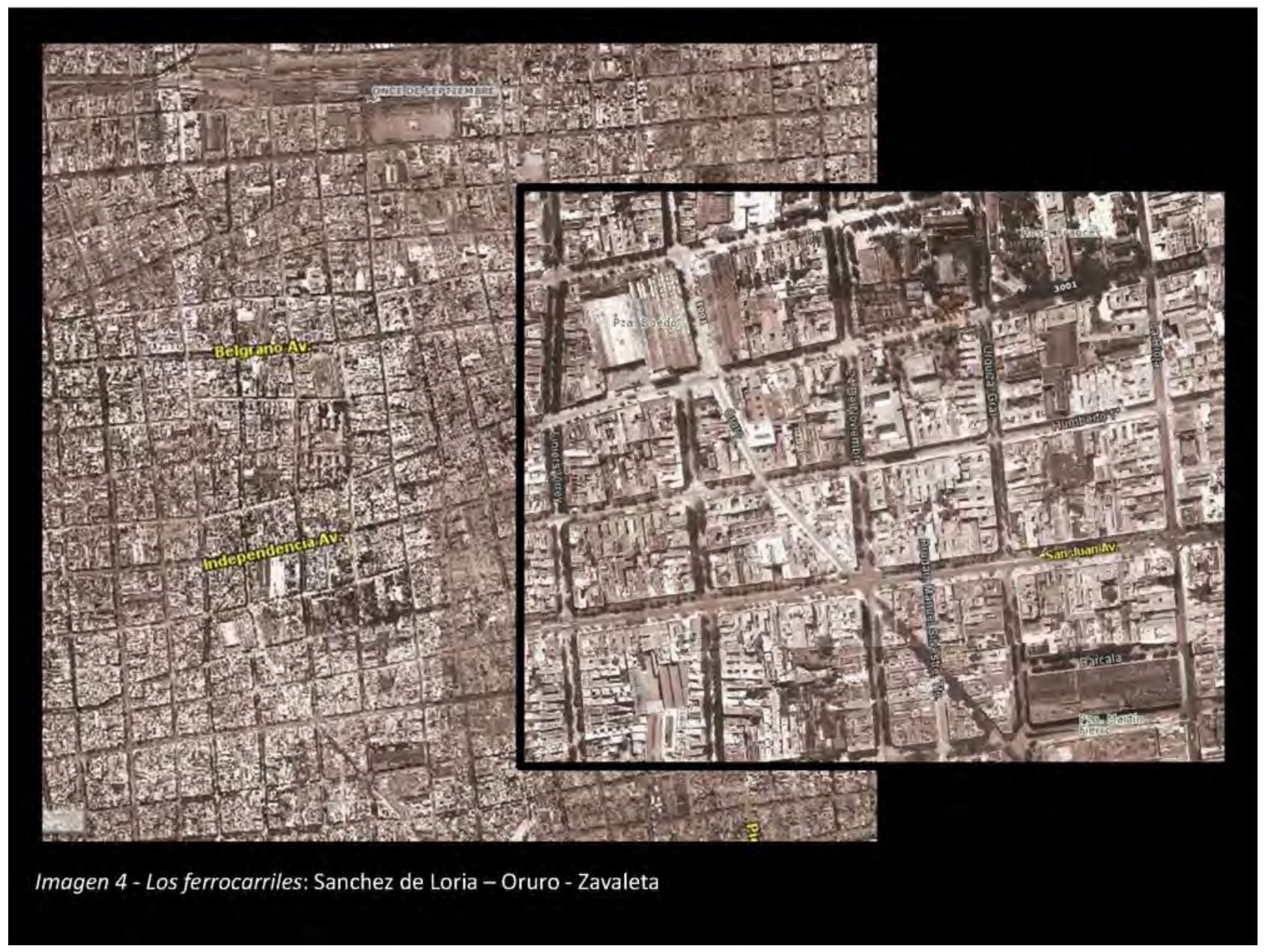

Esto continúa hasta el cruce con la Av. Juan de Garay, donde con el giro final de la curva mencionada, la huella pasa a conformar la calle Deán Funes con rumbo marcadamente Sur.

Esta calle, vuelve a parecerse al primer tramo, de lo que denominé huellas visibles pero simples, evidente en el correlato de una vía de circulación. El cambio con la calle Zabaleta, no responde a cuestiones morfológicas, sino que simplemente la misma arteria cambia de nombre al cruzar la Av. Caseros.

La calle Zavaleta correrá entonces en sentido sur, sin grandes cambios continuando con la lógica de 
calle ahora corriendo en paralelo a las vías del tren Roca, dado que desde la Estación Buenos Aires hacia el sur, el ramal no fue desafectado, aunque sí modernizado. Pueden verso entonces, las vías en funcionamiento actual desde la Av. Iriarte hasta el cruce del Riachuelo.

En el tramo final dentro de la Ciudad de Buenos Aires, tanto la calle como la vía férrea quedaron inmersas en medio del crecimiento orgánico del Barrio 21/24 originado como un asentamiento precario y oficializado y comenzado a urbanizar recientemente. La proximidad de las viviendas construidas sin consideración de los espacios requeridos para la libre circulación de las formaciones, obligó a la relocalización de algunas familias, para evitar que el tren afectara sus viviendas como a ellos mismos.

Una vez cruzado el puente metálico sobre el Riachuelo, las vías continúan en la Provincia de Buenos Aires, no así la calle, que termina en la costa. Estas vías, atraviesan y dividen en dos a la península formada por un meandro del Riachuelo, donde se ubica el Club Victoriano Arenas, cuya cancha de fútbol se encuentra lindando con el terraplén de las vías.

Continuando hacia el sur, las vías tienen un giro nuevamente hacia el este a la altura del Intercambio Midland. Es en este rumbo que continuando recto, cruzan otro ramal del propio ferrocarril Roca, rodea las canchas del Club Atlético Independiente y el Racing Club en la localidad de Avellaneda y luego de una serie de curvas y contra curvas adquiere su rumbo final hacia el noreste.

El ramal, termina así en el puerto de inflamables de Dock Sud. Claro está que las actuales vías férreas nada tienen que ver con las originales del tren de la basura. Pero la huella del ferrocarril es la misma, solo que ahora por tramos ha sido desmantelado y originado calles y avenidas y en otros tramos la misma huella justifica el recorrido de ramales férreos más nuevos, con otros objetivos y distintas justificaciones de cambios de direcciones.

\section{Canard}

Así como hay huellas más visibles, las hay menos visibles. En el barrio de Palermo, hay un sector entre la calle Humboldt y la calle Amenábar, ya casi entrando en el lindero barrio de Colegiales donde en forma intermitente aparecen pequeños indicios de situaciones particulares de la trama urbana.

Calles diagonales en medio de una manzana ortogonal, lotes con formas irregulares y plazoletas triangulares son las partes visibles de algo más grande casi imperceptible.

El primer tramo, en la manzana comprendida por la calle Humboldt, Aguirre, Fitz Roy y Loyola, presenta un estacionamiento a cielo abierto cuyos bordes toman en parte tres calles pero el cuarto límite es una medianera diagonal aproximadamente por la mitad de la manzana que lo separa de los lotes frentistas a la calle Fitz Roy.

Le sigue el caso de la calle Canard, únicos cien metros transitables de esa huella más grande. La manzana delimitada por las calles Loyola, Bonpland, Castillo y Fitz Roy en Palermo, presenta un corte diagonal producido justamente por la calle Dr. Benjamín Canard. Esto genera un lote triangular exento hacia el sureste y un polígono más irregular en el lado opuesto.

La manzana siguiente (Fitz Roy, Castillo, Bonpland y la Av. Córdoba) no presenta un corte visible, pero si se observan los límites de los terrenos o la morfología de sus techos, se evidencia en una franja unas líneas diagonales, perfectamente alineadas con la dirección de las observaciones anteriormente detalladas.

En la manzana siguiente, configurada por las calles Bonpland, Castillo, Carranza y la Av. Córdoba, la huella vuelve a ser visible. Dado que esta línea que se viene describiendo, pasa muy cercana a la esquina, y el espacio "residual” era muy pequeño para ser loteado, es que se forma la Plazoleta Agustín Comastri. 
De aquí en más, las manzanas subsiguientes carecen de huella visible para resaltar sólo lo que he llamado huella invisible, solo detectable como se dijo en los límites entre lotes o en la conformación de techos, azoteas y medianeras.

Es en estas manzanas donde si seguimos esta mencionada "línea” en cartografía de catastro o en imágenes aéreas de la zona, encontraremos que las manzanas contiguas presentan parcelas "diagonales” que cortan a la trama ortogonal habitual, generando lotes y edificaciones que teniendo acceso por las esquinas, ocupan los centros de manzana, algunas incluso son pasantes de ochava a ochava.

Nos encontramos entonces ante la huella de otro ramal de interconexión entre distintos ferrocarriles, como en algunos casos ya mencionados. En este caso entre los actuales Ferrocarril Mitre y el Ferrocarril San Martín, que mediante una curva en la unión Sur, un tramo recto en sentido Noreste y otra curva de vinculación Norte, permitía el paso de trenes por los diferentes ramales.

Al desmantelarse las vías, en lugar de abrir una vía de comunicación vehicular en toda su extensión, en este caso se optó por mantener solo 100m en el extremo Sur, transformándose en la calle Canard y el resto de la traza fue loteada y vendida como parcelas del catastro. Las mismas fueron adquiridas por privados, se realizaron construcciones y hoy solo puede evidenciarse tal situación, o bien analizando los planos de parcelas o encontrando ciertas direccionalidades y cambios en los techos, patios y medianeras.

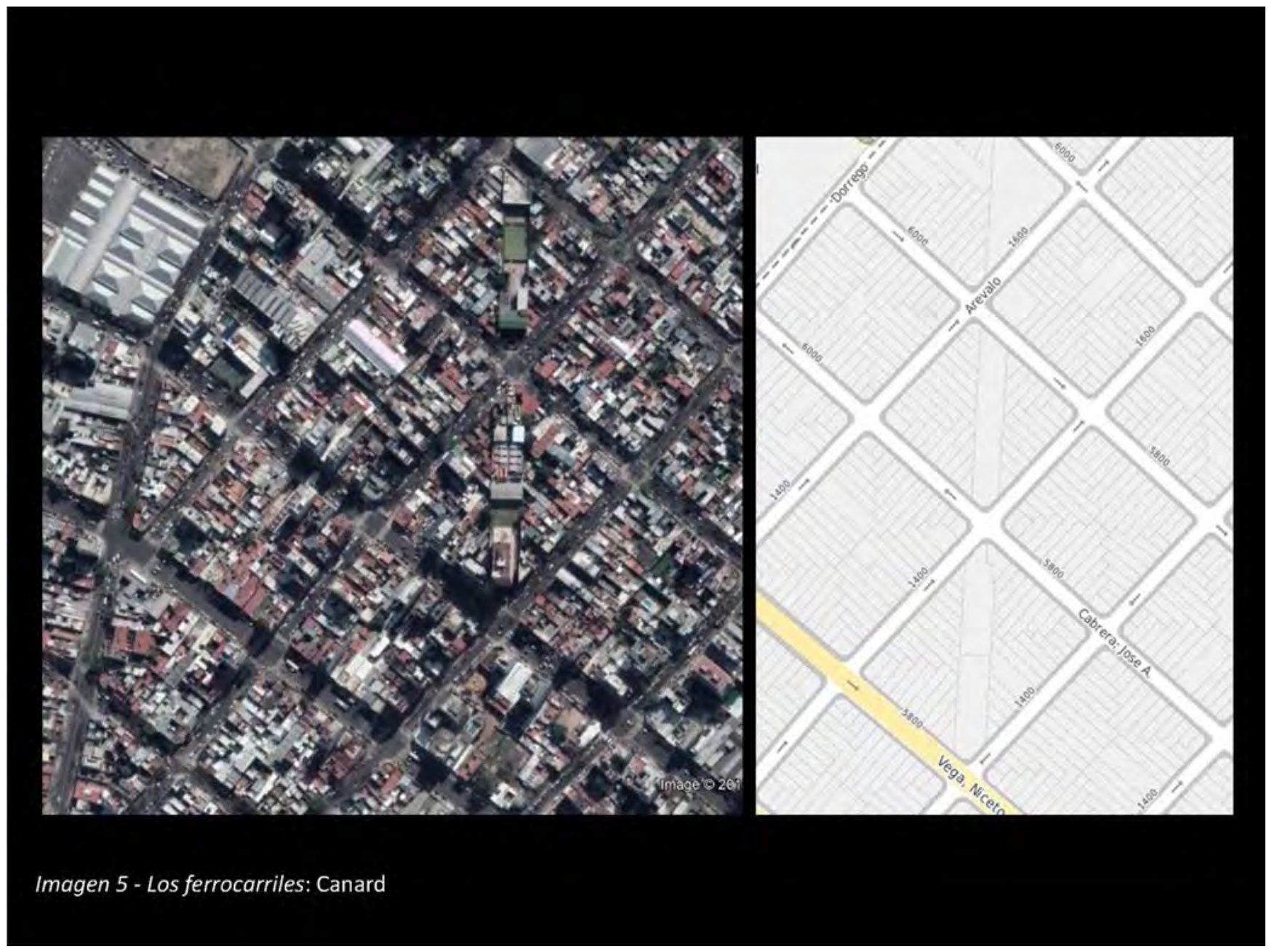


La esquina de Niceto Vega y Carranza, presenta por ejemplo la particularidad de tener un edificio en torre (un paralelepípedo regular) cuyo lado más corto coincide con la línea de ochava y el lado largo se interna en la manzana por su diagonal. El jardín de la planta baja, llega hasta la mitad de la manzana y al tener liberado de usos la pisada, puede apreciarse lo distinto que es este lote diagonal con acceso por la esquina en comparación con los lotes tradicionales perpendiculares a las calles que delimitan la manzana.

En la esquina opuesta (Ravignani y Cabrera) ocurre algo similar, pero por la característica de la construcción más compacta, no es tan evidente que se trata de una edificación ganada o recuperada a un antiguo espacio de circulación férreo.

La manzana que sigue, me es especialmente particular. Por varios motivos, en principio porque es precisamente la manzana que hizo que siguiera este "hilo" conductor de particularidades en la trama urbana sin razón aparente y que desembocara en esta búsqueda de justificaciones hallada finalmente en el pasado ferroviario de la ciudad.

Es que en esta manzana, todo a lo largo de la "traza” o sea nuevamente la diagonal de la manzana de ochava a ochava, se presenta un único lote. Actualmente está ocupado por un colegio, que tiene construcciones edificadas sobre las esquinas, liberando el centro como patio y lugar deportivo. Sin embargo al estar comunicados, uno puede ingresar por una ochava, recorrer todo el predio y salir por la otra. Esto no es común en ninguna parcela, salvo claro en aquellos pasajes que tanto abundan en la ciudad, pero que por lo general se trata de cortes ortogonales con la trama tradicional de la ciudad.

Las siguientes dos manzanas, presenta una a derecha y la otra a izquierda edificaciones que de alguna forma dejan ver las medianeras diagonales y delatan la presencia de un pasado distinto.

En la manzana final de esta trama, donde puede verse otro vestigio de este pasado más industrial del barrio y que justifica en parte la necesidad de estas conexiones ferroviarias. Se trata de los Silos de Dorrego, unos antiguos silos de acopio de granos, que ahora han sido reciclados y reconvertidos en departamentos.

La dirección de los silos en la manzana, hoy parece arbitraria, sin embargo continuando con la línea directriz de todo lo descripto hasta ahora, se entiende que su posición en el terreno obedece claramente a estar paralelos a las vías del ferrocarril donde seguramente tenían su conexión interna para abastecer de carga a las formaciones.

El tramo final, claramente toma nuevamente una curva para vincularse con el ferrocarril Mitre, espacio que perteneciendo siempre al estado es ocupado hoy por una planta de compactación y traspase de residuos usufructuada por el Seamse.

\section{Arroyos y Terceros}

El segundo tipo de casos formadores a mi entender de huellas urbanas, es el caso de los arroyos o terceros que desaguan las lluvias de las partes más altas de la ciudad hacia el Río de la Plata.

Las cuencas hidrográficas de la ciudad, no son tan numerosas pero evidencian que la misma no es tan plana o "chata" como suele pensarse habitualmente como consecuencia de la llegada de la llanura pampeana a la costa. Es evidente que la orografía de la ciudad, si presenta elevaciones y depresiones importantes justo en consecuencia con las cuencas.

Poco podemos ver hoy de los arroyos, dado que en épocas pasadas se los consideraba casi cloacas a cielo abierto y en vez de sanearlos y evitar el volcado de aguas residuales, se determinó que lo más eficiente para hacer era taparlos y dejar de verlos. Como si eso evitara sus problemas.

Por un lado se contuvo parcialmente las inundaciones, hasta que el avance de la ciudad y la saturación 
del suelo con cada vez más asfalto y concreto en espacios públicos como privados comenzó a ser perjudicial y con el aumento de las precipitaciones los arroyos ya no fueron contenidos por sus entubados y las anegaciones volvieron.

El aprovechamiento de los espacios residuales dejados por los ahora entubados arroyos, fue adjudicado en mayor medida a generar nuevas vías de circulación por sobre los mismos.

\section{El Cildañez}

El arroyo Cildañez corre bajo algunas calles y avenidas de la Ciudad, desde la Av. General Paz, su traza corre bajo la calle Justo Antonio Suarez, tiene un desvío por la calle Murguiondo para sortear los corrales de los viejos mataderos, luego corre por la calle Remedios donde toma una curva buscando el Riachuelo y la vía pasa a llamarse Av. San Juan Bautista de La Salle, luego de una curva final cambia su nombre por el de Av. Asturias por la que continúa en forma recta hasta su desembocadura en un canal abierto en el Parque Roca.

Seguir el trazado del arroyo en cartografía de la década del '40, hecha luz sobre la morfología de las actuales calles mencionadas y ayuda a entender las tramas y vías de circulación que salen de los diseños ortogonales habituales.

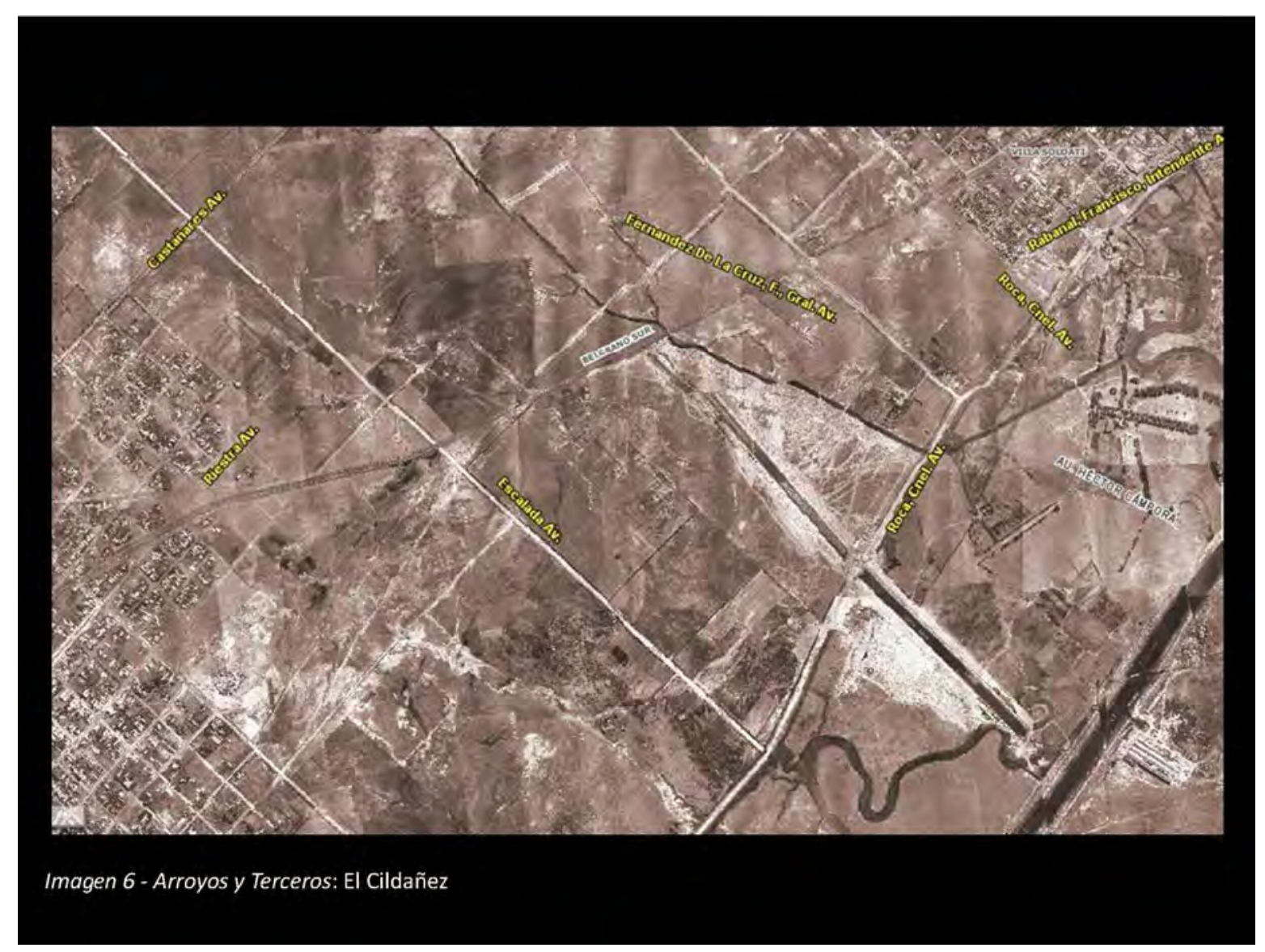

En el primer tramo, el de la calle Suárez entre Gral. Paz y la Av. Lisandro de la Torre, el arroyo corría en sentido Oeste-Este, las calles que lo cortaban tenían pequeños puentes para cruzarlo pero no tenía una 
calle paralela al trazado, lo que justifica que tras su entubado en la década del '50 el propio trazado del arroyo se haya convertido en la actual arteria.

La zona de los corrales de los mataderos, con una superficie importante que corta varias de las calles de la trama urbana circundante, obligó al desvío con curvas y contra curvas a $90^{\circ}$ del arroyo para que pueda continuar ahora por la calle que hoy se denomina Remedios.

En esta calle, nuevamente el curso de agua discurre recto en sentido SurOeste-NorEste y no presenta calle accesoria, justificando nuevamente la decisión de entubarlo y generar por sobre él una vía de circulación. Queda claro que además de la ventaja circulatoria, otros factores como la inundación y la pérdida de producción y mercaderías asociadas a esto, seguramente justificaron su entubamiento.

Entre las actuales calles Araujo y Basualdo, el lecho presentaba una curva pronunciada hacia la derecha, buscando la desembocadura natural en el Riachuelo.

Luego de esta curva, la nomenclatura cambia a Av. San Juan Bautista de La Salle ahora con sentido más franco Oeste-Este y mediante una nueva curva que lleva la dirección más cercana a Norte-Sur, esta se transforma en la Av. Asturias. Esta avenida, cruzando su continuación virtual en medio del Parque Indoamericano, el complejo de juegos mecanizados que anteriormente era el Parque de la Ciudad y finalmente el Parque Roca termina por verse ahora como un canal a cielo abierto para luego desembocar en el Riachuelo.

Comparando las imágenes del trazado del arroyo y superponiéndolas con la traza de las actuales calles que corren por sobre la obra de entubado, hay una clara literalidad entre una otra imagen.

Las calles no son más que una gran huella que permite hoy en día, saber cómo era exactamente el trazado del curso de agua.

\section{El Maldonado}

Uno de los más conocidos arroyos de la Ciudad, es sin dudas el Maldonado, ya que hasta hace poco sus salidas del cauce entubado generaban numerosas inundaciones en los barrios que atraviesa. Desde hace unos años y tras la construcción de dos canales aliviadores bajo su traza original, esto cesó.

El arroyo figura tanto en cartografía, como en fotografía aérea discurriendo a cielo abierto a lo ancho de toda la ciudad, dado que su origen está en realidad en la vecina Provincia de Buenos Aires hacia el Oeste y desemboca en el extremo Este en el Río de la Plata.

Además es mencionado en cuentos, historias, canciones y hasta incluso leyendas, desde sus inicios como el caso de su propio nombre, supuestamente relacionado con una española de apellido Maldonado que arribara con Don Pedro de Mendoza en 1536 a la que leyenda mediante, se supone le ocurrieron vicisitudes en las inmediaciones del arroyo.

Tal era el caudal de agua que transportaba el arroyo, que durante décadas desde la fundación de la Ciudad, funcionó como límite natural de protección de la misma. Cuando ésta empezó a crecer, sobre todo en su eje o corredor Norte por la costa, lo que hoy es la Av. Santa Fe y su continuación Cabildo, el arroyo con su voluminoso caudal comenzó a verse más como un problema que una protección.

Sortearlo en ocasiones era complicado y no abundaban en un principio los puentes para cruzarlo, dado que las correntadas producto de las crecientes en los períodos de lluvia arrasaban con la estructura de soporte de los mismos. Tras varias reconstrucciones, se comenzaron a acumular puentes nuevos al lado de puentes viejos. Es interesante ver en fotografía de época y cartografía, estos puentes que lo cruzaban para facilitar su cruce y cómo la ciudad recuperó conexiones Norte-Sur tras su entubamiento, pero se vio perjudicada por su caudal no siempre controlable. 
Hacia la década de 1930 se decide que la ciudad no debe soportar más las inundaciones producidas por el arroyo y comienza un lento proceso de entubado de su cauce consistente en construir gruesos muros de mampostería en las barrancas del arroyo y una "tapa” conformada por bóvedas de ladrillo, sobre la cual se colocaría tierra y luego el pavimento de una nueva vía de circulación que permitiría a su vez la conexión Este-Oeste.

Es así que las actuales Av. Juan B. Justo, desde su nacimiento en la Av. General Paz y en todo su recorrido hasta la Av. Santa Fe y su continuación la Av. Bullrich desde Santa Fe hasta Libertador, donde cambia de nombre a Av. Dorrego y ésta hasta su intersección con la Av. Lugones, representan cabalmente la traza original del arroyo hasta su desembocadura en el Río de la Plata.

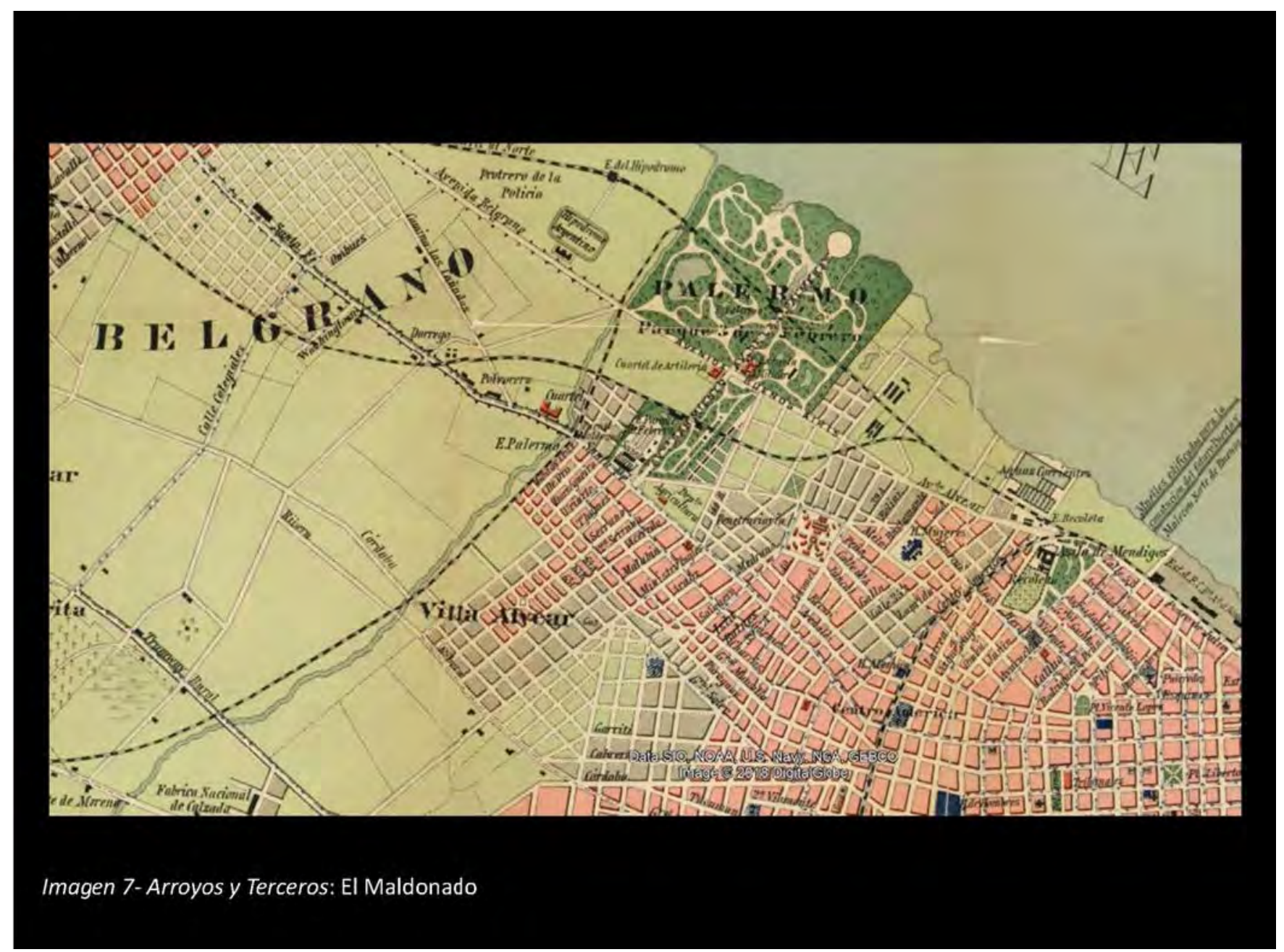

Un último tramo del arroyo ahora entubado transcurre, sin evidencias superficiales, bajo el predio del Aeroparque Jorge Newbery y más precisamente bajo la pista de aterrizaje del mismo hasta cruzar la Av. Costanera Rafael Obligado y ahí si finalmente desaguar al río.

Pese a no tener una huella urbana visible en este tramo, resulta interesante casi como anécdota que esta particularidad que haya un entubamiento bajo la pista del aeroparque, les permitió en la década del 1970 a un grupo de terroristas del ERP, adentrarse en el tubo del arroyo y poner dos explosivos de gran poten- 
cia destinado a ser detonado cuando estuviera en la pista despegando el General Videla, presidente de facto de la Nación en lo que fue llamado “Operación Gaviota”, no habiendo tenido éxito en su cometido.

En el resto de las avenidas mencionadas, si puede evidenciarse la huella del viejo arroyo en la superficie. Es que la Av. Juan B. Justo presenta a lo largo de su recorrido cambios repentinos como giros y desvíos que a priori parecen caprichosos. Más cuando se analiza la traza de la avenida comparándola con la trama urbana ortogonal circundante y se evidencia así que el recorrido de la avenida no solo nada tiene que ver con la misma, sino que parece intencionalmente puesta cortando en diagonal a todas las manzanas que atraviesa. Claramente no se trata de un original o particular diseño de vías circulatorias, sino que la avenida no hizo más que aprovechar el espacio lineal vacante producido por el entubado del arroyo.

Lo mencionado anteriormente de la sucesión de puentes que lo cruzaban, tomó relevancia en los años 1990 y 2000, cuando se descubrió que además del factor de saturación de la capacidad de escurrimiento de agua del centenario entubado y sumado al cambio de regímenes de lluvias más frecuentes y más violentas, comenzó a verse con más frecuencia la salida de cauce y con ello la inundación de numerosas cuadras del entorno inmediato al arroyo. Es que se descubrió que al construir las estructuras para el entubado, no todos los puentes habían sido demolidos, sino que estaban en parte aún dentro del entubado. Como paliativo se decidió su remoción para permitir un mejor fluir de las aguas.

Esto claramente fue insuficiente con un clima cada vez más tendiendo a lo subtropical, lo que obligó a partir del año 2007 a iniciar una impresionante obra de ingeniería que mediante el uso de dos grandes excavadoras autónomas construir dos túneles aliviadores que corren aún más abajo del cauce original y mediante algunos pozos de interconexión permiten aliviar la carga del emisario principal.

El trazado “cortando camino" del arroyo y por ende de la Avenida, origina en la traza actual, una sucesión de manzanas atípicas, casi de forma triangular y en aquellas que no se las consideró lo suficientemente grandes para ser loteadas, se las destinó a plazoletas o plazas que se suceden a ambos lados de la avenida.

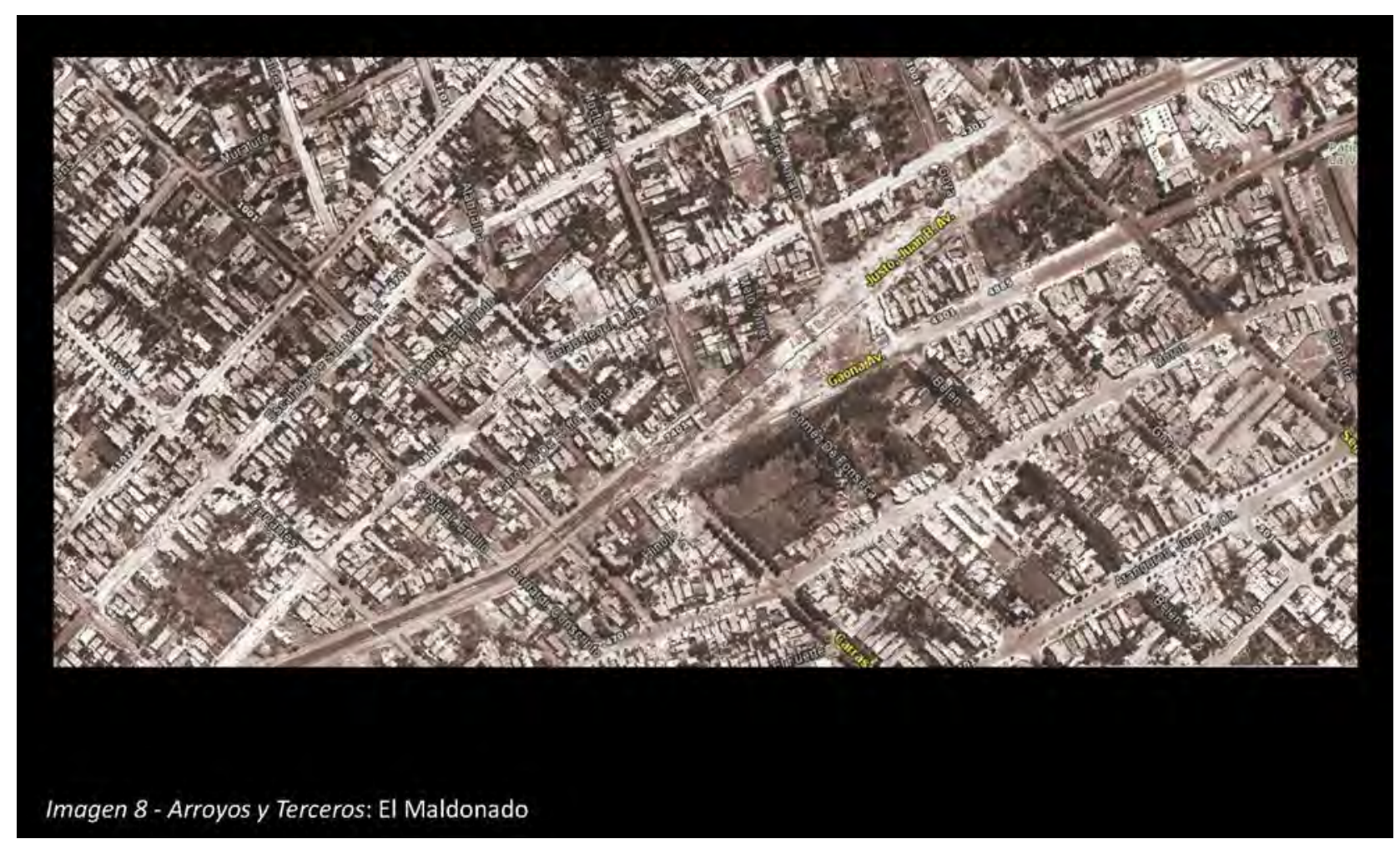


Es interesante destacar en la fotografía aérea de 1940 como todavía pueden apreciarse los tres estadios de la obra del ocultamiento del arroyo. Cercano a la Av. General Paz, se observa como el arroyo discurre aun a cielo abierto sin noticias de la modernidad del entubado. En el sector central, en coincidencia con el cruce con la Av. Gaona, se encuentra el límite del arroyo abierto con la estructura de cobertura y los movimientos de suelos por sobre el mismo. Unas cuadras más adelante, encontramos ya la ancha Avenida con boulevard central como si nada pasara por debajo de ella.

Recientemente la avenida recibió una de sus últimas transformaciones, al incorporarse en toda su extensión un Metrobus en los carriles centrales, lo que cambió no solo su fisionomía sino que ordenó su tránsito entre el transporte público que circula el medio y los vehículos particulares que corren por los costados. Más recientemente aún, se decidió invertir los roles de circulación de la avenida por sobre el Ferrocarril San Martín, elevando las vías de éste y “bajando” la traza de la Avenida para que corre siempre a nivel. Esto obliga a demoler el puente de la Reconquista, construido en la década de 1960 y una vez demolido, quedará el cruce a nivel de las Av. Juan B. Justo y Córdoba y el FFCC San Martín correrá en viaducto por arriba. Estas obras están en plena ejecución y se espera su culminación para mediados del año 2019.

\section{Fútbol por Turf}

Finalmente, de los tres casos o tipos de “generadores” de huellas urbanas, presento aquí el último de los que analizaré.

Se trata de otros elementos que suelen definir la morfología urbana, las instalaciones deportivas. El turf fue en el pasado una de las actividades que más multitudes atraía y dada la concurrencia de grandes cantidades de público, debían hacerse instalaciones cada vez más grandes y cómodas para alojarlos. Por lógica al tratarse de carreras de caballos, se necesitaba por un lado grandes extensiones donde montar una pista que a nivel mundial se estilaba de unos 2000mts de longitud (entre rectas y codos) y por otro lado un lugar donde albergar los caballos que en ellas correrían. Esto hizo que en la mayoría de las ciudades los hipódromos estén en las afueras de la trama urbana, donde se conseguía dichas extensiones de campo.

Así fue el caso del Hipódromo Nacional, inaugurado hacia 1886 en unos terrenos “alejados” del centro de la ciudad, pero próximos al por ese entonces pueblo de Belgrano (previo a su incorporación a la Ciudad de Buenos Aires y pasar a ser considerado un barrio de ésta en lugar de un poblado independiente). Unos terrenos vacantes entre la Avenida Belgrano (hoy Del Libertador) y la costa del Río de la Plata, sería el solar elegido.

Hacia 1911, los propietarios del Hipódromo Nacional, se asocian con quienes tenían la concesión de un sector del Parque 3 de Febrero y deciden construir en esas tierras de Palermo una nueva pista, el Hipódromo Argentino. El mismo que se mantiene hasta nuestros días en el mismo lugar y es conocido ahora como Hipódromo de Palermo.

Se decide entonces cerrar el Hipódromo Nacional, para unificar las carreras en el flamante Hipódromo Argentino. Pese a esto, algunas de las instalaciones se mantienen durante algunos años, usando la pista como vareo y práctica para las carreras de Palermo.

Tras desmantelar la pista así como algunos de los equipamientos accesorios, el terreno quedó vacante nuevamente, hasta que entre las décadas del '20 y del '30 comienza la idea de lotearlas y así integrar dichas tierras a la trama urbana. Hacia 1938 además se inician las obras del nuevo estadio de fútbol del Club Atlético River Plate, que ocuparía la zona más cercana al río del viejo Hipódromo, dejando por algunos años también libres los terrenos hacia la Av. Del Libertador. 
Teoría y Práctica de la Arqueología Histórica Latinoamericana | Año VIII. Vol. 9 | 2019

ISSN en línea: 2591-2801 | ISSN versión impresa: 2250-866X

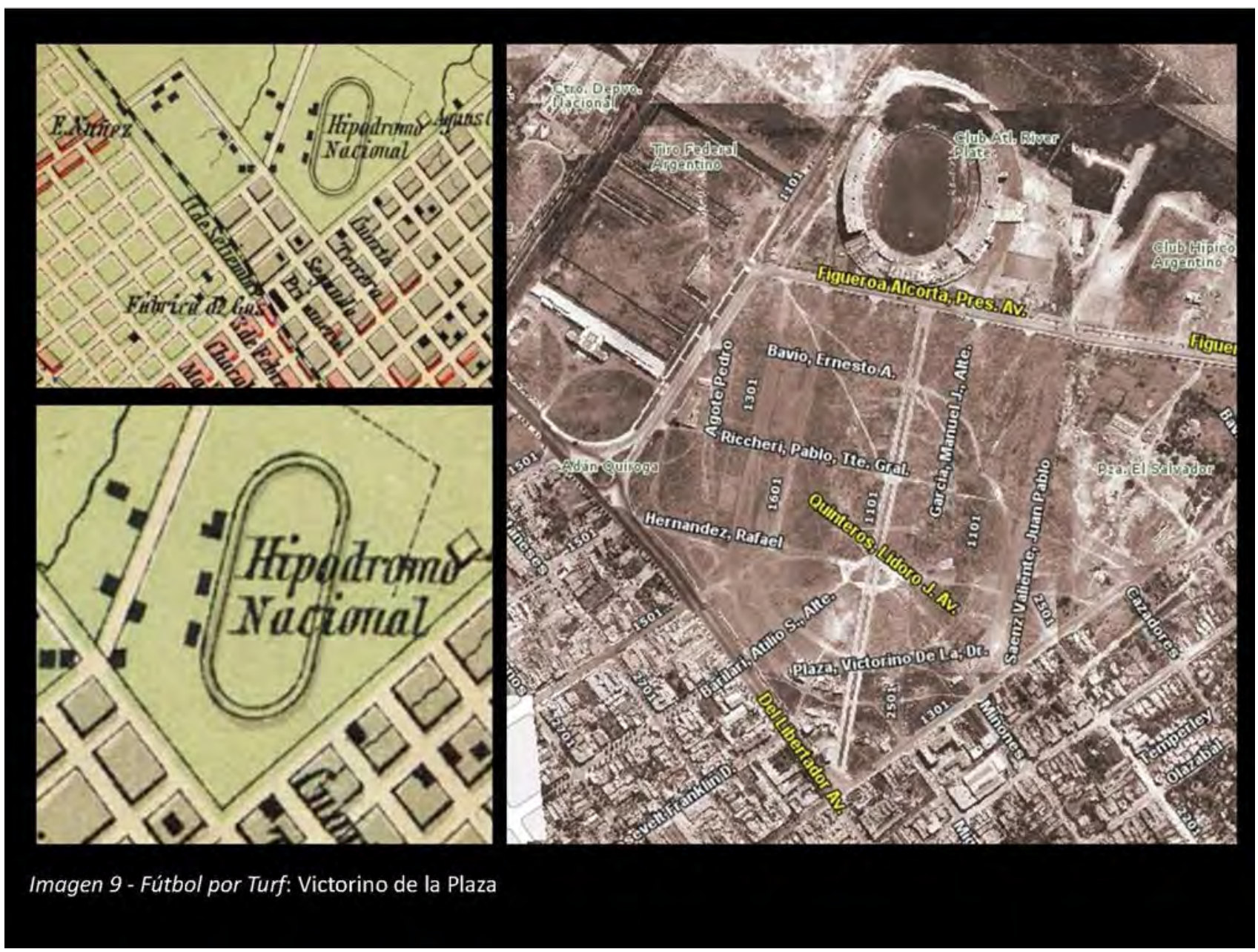

Actualmente esos terrenos forman parte del barrio de Belgrano, más precisamente el Barrio Parque Manuel Belgrano, comúnmente llamado "Barrio River”, por la cercanía con el mencionado Estadio.

La ubicación del óvalo de la pista del hipódromo, con una rotación respecto de la trama urbana lindante, es imperceptible en la zona del actual estadio dado que la cancha y sus tribunas no están exactamente en el "codo" de la pista pero por la forma del estadio, actualmente pareciera que estuviéramos viendo parte de la vieja traza. No lo es, pero está muy cerca.

En el extremo sur, en cambio si se evidencia claramente en la actualidad la traza de la vieja pista del hipódromo, dado que la calle Victorino de la Plaza, toma la forma semicircular del viejo codo.

En las fotografías aéreas de 1940 puede verse ya el estadio de River Plate con sus tribunas como fuera inaugurado en la década del '30 y las que conservó en esa forma hasta el Mundial de 1978 donde se completó el anillo con la tribuna que da al Río. En ella además se observa ya la apertura de algunas calles del Barrio Parque Manuel Belgrano, pero por sobre todas las cosas se evidencia la traza de la vieja pista del hipódromo, con tierra removida producto de su eliminación y posterior conversión en la calle Victorino de la Plaza.

Esta calle, que nace perpendicular a la Avenida Figueroa Alcorta, se dibuja en un principio sobre una de las rectas de la vieja pista, luego la calle toma la forma del codo para luego volver a tomar la recta y desembocar nuevamente en Figueroa Alcorta. Curioso caso, que además de copiar un trazado antiguo, la calle nace y muere en la misma avenida con unos escasos 200mts de diferencia. 
Teoría y Práctica de la Arqueología Histórica Latinoamericana | Año VIII. Vol. 9 | 2019

ISSN en línea: 2591-2801 | ISSN versión impresa: 2250-866X

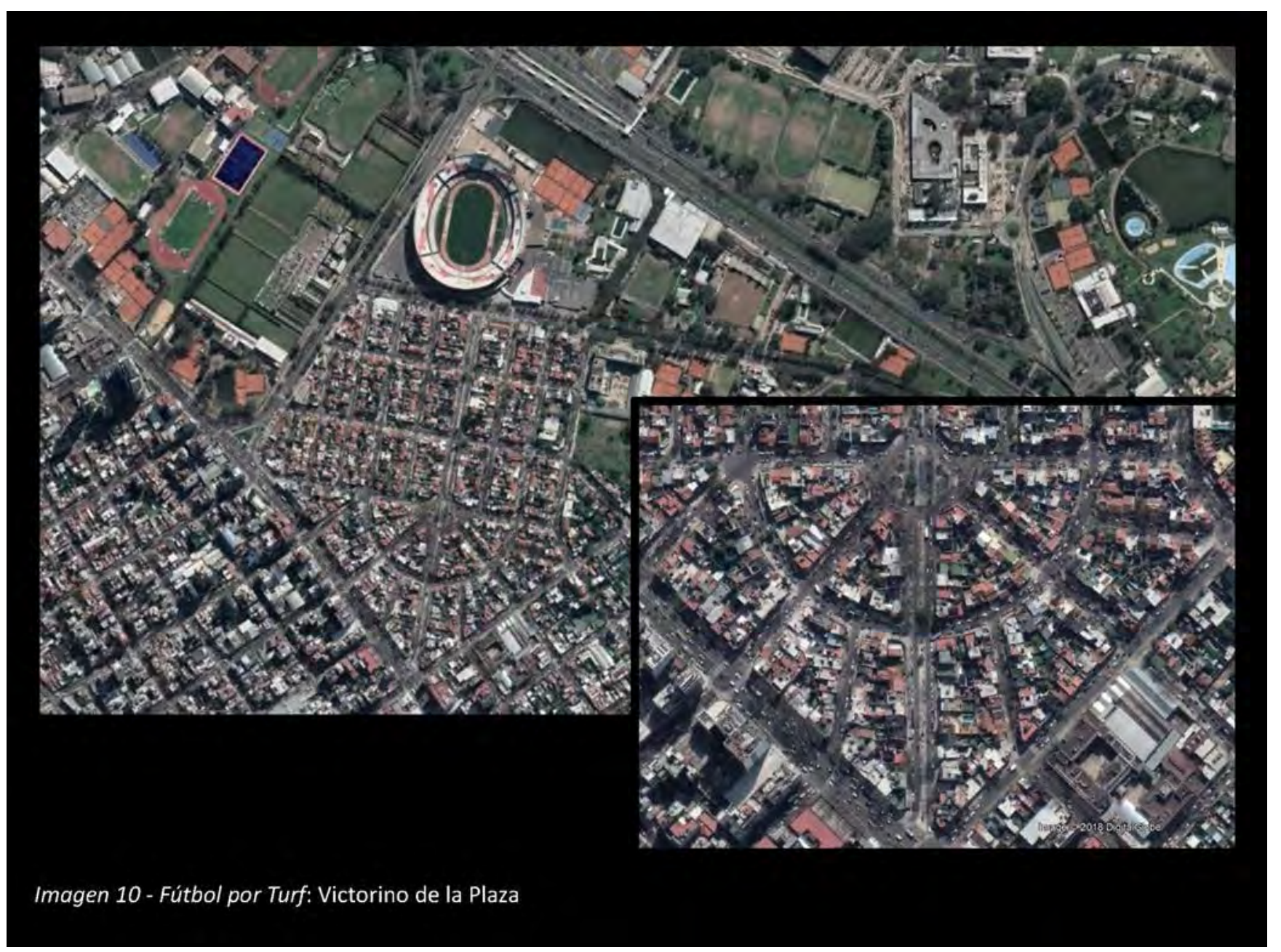

Por ese entonces, no existía aún el Ferrocarril Belgrano que hoy es el más próximo a la zona, pero si funcionaba el Ferrocarril del Norte, hoy Mitre cuya estación Belgrano "C" ubicada en las Barrancas de Belgrano no distaba mucho del Hipódromo. Para acercar al público, se había instalado una línea de tranvías que unía el hipódromo con esta estación y se ofrecía un servicio gratuito tanto de ida como de vuelta.

Aquellos apostadores que habían perdido todo en la jornada, podían igualmente tomar el servicio gratuito hacia el ferrocarril, pero por falta de dinero no podían abordar este último. Esta particular situación de jugadores sin más dinero para volver, dio origen a la expresión de quedarse en "Pampa y la vía”, dado que ahí terminaba el servicio gratuito y comenzaba el pago. Dicha expresión de quedarse sin dinero, o varado se sigue usando hasta nuestros días, aunque seguramente ignorando su origen.

\section{Reflexiones finales}

Como expresé al principio, me pareció interesante en mi aporte como arquitecto y amante de la historia urbana de la Ciudad de Buenos Aires traer algunos casos donde elementos del pasado, no siempre visibles o prefigurables en la actualidad y que en apariencia no responden a lógica alguna encuentran en elementos del pasado su justificación.

En un intento por indagar en hechos pasados, que son netamente visuales de entender y comprender 
en la trama urbana, me vi inmerso en una excavación virtual en cartografía de diferentes épocas con el fin de probar los orígenes de ciertas cosas para así encontrar las marcas del pasado presentes hoy. Es así que pude presentar estas pocas pero interesantes huellas urbanas que sin duda dejaron su impronta en el paisaje urbano actual.

\section{Notas}

${ }^{1}$ https://www.lexico.com/es/definicion/huella

\section{Referencias bibliográficas}

NOGUÉS, G. (2003). Buenos Aires, Ciudad Secreta. Buenos Aires, Argentina: Sudamericana. SCOBIE, J.R. (1974). Buenos Aires, plaza to suburbs, 1870-1910. Oxford, Reino Unido: Oxford University Press. Traducción de Williams, M. (1977) Buenos Aires, Argentina: Solar/Hachette INSTITUTO HISTÓRICO DE LA CIUDAD DE BUENOS AIRES. (2003) Guía de Cartografía Histórica de la Ciudad de Buenos Aires, 1854-1900. Buenos Aires, Argentina.

\section{Imágenes utilizadas}

Google Earth

- 1892 - Rumsey Historical Maps, mapa Pablo Ludwig, Cartógrafo.

- 2018 - Digital Globe

Mapa Interactivo de la Ciudad de Buenos Aires

- 1940 - Fotos aéreas

- 2018 - Catastro parcelario

Recibido: 10 de junio de 2019

Aceptado: 20 de septiembre de 2029 